\title{
DNA Damage and Radical Reactions: Mechanistic Aspects, Formation in Cells and Repair Studies
}

\author{
Jean Cadet $^{\star a}$, Thomas Carell ${ }^{b}$, Luciano Cellaic, Chryssostomos Chatgilialoglud, \\ Thanasis Gimisis ${ }^{\mathrm{e}}$, Miguel Miranda ${ }^{\mathrm{f}}$, Peter O’Neillg, Jean-Luc Ravanat ${ }^{\mathrm{a}}$, and Marc Robert ${ }^{\mathrm{h}}$
}

\begin{abstract}
Several examples of oxidative and reductive reactions of DNA components that lead to single and tandem modifications are discussed in this review. These include nucleophilic addition reactions of the one-electron oxidation-mediated guanine radical cation and the one-electron reduced intermediate of 8-bromopurine 2'-deoxyribonucleosides that give rise to either an oxidizing guanine radical or related 5',8-cyclopurine nucleosides. In addition, mechanistic insights into the reductive pathways involved in the photolyase induced reversal of cyclobutadipyrimidine and pyrimidine (6-4) pyrimidone photoproducts are provided. Evidence for the occurrence and validation in cellular DNA of ${ }^{\circ} \mathrm{OH}$ radical degradation pathways of guanine that have been established in model systems has been gained from the accurate measurement of degradation products. Relevant information on biochemical aspects of the repair of single and clustered oxidatively generated damage to DNA has been gained from detailed investigations that rely on the synthesis of suitable modified probes. Thus the preparation of stable carbocyclic derivatives of purine nucleoside containing defined sequence oligonucleotides has allowed detailed crystallographic studies of the recognition step of the base damage by enzymes implicated in the base excision repair (BER) pathway. Detailed insights are provided on the BER processing of non-double strand break bistranded clustered damage that may consist of base lesions, a single strand break or abasic sites and represent one of the main deleterious classes of radiation-induced DNA damage.
\end{abstract}

Keywords: Base excision repair · DNA · Guanine radical cation · Pathway

${ }^{*}$ Correspondence: Prof. Dr. J. Cadet ${ }^{a}$

Tel.: + 33438784987

Fax: + 33438785090

E-mail: jean.cadet@cea.fr

aLaboratoire des Lésions des Acides Nucléiques

SCIB-UMR-E $n^{\circ} 3$ (CEA/UJF)

Institut Nanosciences et Cryogénie

CEA/Grenoble

F-38054 Grenoble Cedex 9, France

${ }^{b}$ Center for Integrative Protein Science

Department of Chemistry and Biochemistry

Ludwig Maximilians University Munich

81377 Munich, Germany

CIstituto di Cristalografia

Consiglio Nazionale delle Richerche

I-00016 Monterotondo Stazione

Rome, Italy

dISOF

Consiglio Nazionale delle Ricerche

40129 Bologna, Italy

eOrganic Chemistry Laboratory Department of

Chemistry

National \& Kapodistrian University of Athens

15784 Athens, Greece

fDepartamendo de Quimica

Instituto de Technologia Quimica

Universidad Politéchnica de Valencia

46022 Valencia, Spain

gRadiation Oncology \& Biology

University of Oxford

Oxford OX3 7DQ, UK

hLaboratoire d'Electrochimie Moléculaire

UMR-CNRS N7591

Université Paris 7-Denis Diderot

75251 Paris Cedex 05, France

\section{Introduction}

Radical reactions are strongly implicated in the generation of oxidatively generated DNA damage including tandem and clustered modifications of the bases ${ }^{[1]}$ and/or sugar moieties.[2] Evidence has been also provided for the occurrence of reductive processes in the effectiveness and fidelity of repair of base lesions such as bipyrimidine photoproducts. ${ }^{[3]}$ Relevant information has been gained during the last two decades on the ${ }^{\circ} \mathrm{OH}$ and one-electron oxidant-mediated generation of nucleobase and 2-deoxyribose modifications of DNA model compounds. This has led to the isolation and identification of more than 70 modified nucleosides if one includes diastereomers and thymidine hydroperoxides (for recent reviews see refs $[2,4])$. In contrast there is still a paucity of information on oxidative reactions in cellular DNA that may be explained by the lack until recently of accurate analytical methods able to detect damage formed with a frequency lower or equal to a few residues per $10^{6}$ normal nucleotides. The recent advent of HPLC-MS/MS together with suitable methods of DNA extraction, ${ }^{[5]}$ that have been optimized partly through cooperative efforts within the ESCODD network, ${ }^{[6]}$ has allowed identification of the formation of 15 base and sugar lesions in cellular DNA.[4e,7] Other major research fields aimed at assessing biological importance of DNA damage include DNA repair, ${ }^{[8]}$ polymerase-mediated replication, ${ }^{[9]}$ bypass ${ }^{[10]}$ and mutagenic ${ }^{[1]}$ assessment of oxidatively generated DNA damage. It may be pointed out that a great impetus has been given to the latter activities thanks to the availability of DNA fragments in which dedicated modifications have been site specifically introduced either by insertion or through post-synthesis modification. ${ }^{[12]}$

In the first part of this short review, prepared as the result of cooperative efforts of research groups involved in the EU COST network 'Free Radicals in Chemical Biology', emphasis has been placed on several recent mechanistic studies including both oxidative and reductive chemical reactions of normal and modified DNA compounds. It is worth noting that one-electron reduction of 8-halopurine nucleosides was found to mimic the effects of ${ }^{\circ} \mathrm{OH}$ and one-electron oxidants in generating the 2'-deoxyri- 
bos-5' -yl radical and the oxidizing guanine radical $(\mathrm{G}-\mathrm{H})^{\bullet}$ which may also arise from deprotonation of the guanine radical cation. The second part of the article is devoted to the radiation-induced formation of the two main guanine degradation products in cellular DNA mainly initiated by ${ }^{\circ} \mathrm{OH}$ reactions. Then, in the last section relevant pieces of biochemical information are provided on the recognition of guanine oxidation products and the processing of clustered oxidatively generated DNA lesions by enzymes of the BER pathway.

\section{Mechanistic Studies}

Most of the recent mechanistic studies of oxidatively generated damage to DNA components have been devoted to purine nucleosides and/or nucleotides whereas chemical repair of photo-induced bipyrimidine photoproducts involves reductive reactions.

\subsection{Nucleophilic Addition Reactions Involving the Guanine Radical \\ Cation}

The guanine base, which exhibits the lowest ionization potential among DNA components, is highly susceptible to oneelectron oxidation agents such as ionizing radiation through the direct effect, ${ }^{[13]}$ type I photosensitizers ${ }^{[14]}$ and the biologically relevant nitrosoperoxycarbonate. [15] The guanine radical thus generated is able to undergo two competitive reactions in aqueous solutions. Deprotonation gives rise to $\mathrm{G}(-\mathrm{H})^{\bullet}$ whereas a hydration reaction which was shown to be a major pathway in doublestranded DNA,[14] leads to the formation of the reducing 8-hydroxy-7,8-dihydroguanyl radical (Scheme 1) with a pseudo first-order rate constant of $6 \times 10^{4} \mathrm{~s}^{-1}$.[16]

It was recently proposed, on the basis of molecular dynamics and ab initio quantum calculations, that water molecule addition at $\mathrm{C}(8)$ of the guanine radical cation may be rationalized in terms of a counterion-assisted proton shuttle mechanism. ${ }^{[17]}$ In aerated aqueous solution the neutral guanine radical thus generated reacts efficiently with $\mathrm{O}_{2} \cdot-{ }^{-}\left(\mathrm{k}=4 \times 10^{9} \mathrm{M}^{-1} \mathrm{~s}^{-1}\right)^{[18]}$ leading to the formation of 8-oxo-7,8-dihydroguanine (8-oxo-Gua). In the absence of oxidants and/or in the presence of reducing agents, 2,6-diamino-4-hydroxy-5-formamidopyrimidine (FaPyGua) is formed after oneelectron reduction and subsequent opening of the imidazole ring at the $\mathrm{C}(8)-\mathrm{N}(9)$ bond (Scheme 2). The rate constant for the latter reaction has been estimated to be $2 \times 10^{-5}$ $\mathrm{s}^{-1}$.[18] Additional evidence for the occurrence of nucleophilic addition that is likely to be of biological significance was recently provided by the riboflavin-mediated formation of a cross-link between the central

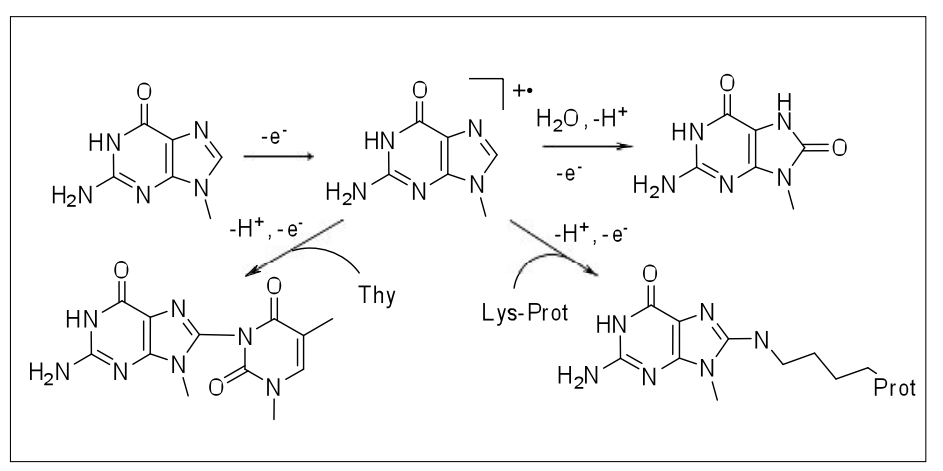

Scheme 1. Nucleophilic addition reactions of the guanine radical cation

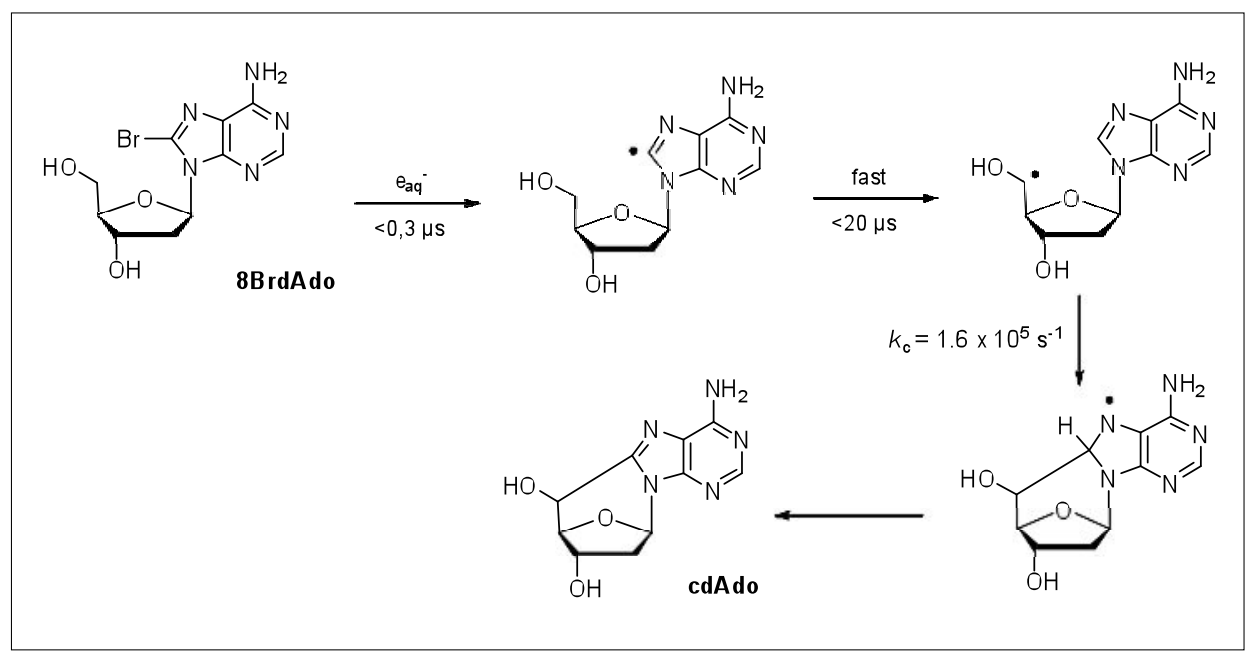

Scheme 2. Formation of 5',8-cyclo-2'-deoxyadenosine from one-electron reduction of 8-bromo-2'deoxyadenosine

lysine of the tripeptide KKK and the guanine moiety of the TpdGpT trinucleotide upon UVA irradiation.[19] The likely mechanism of formation of the DNA-protein adduct involves initial one-electron oxidation of the guanine moiety of the short DNA fragment by a charge transfer reaction involving triplet excited photosensitizer followed by nucleophilic addition of the free amino group of the lysine residue and ultimately by an oxidation reaction mediated by $\mathrm{O}_{2}$. It may be pointed out that the covalent attachment of KKK peptide to the short oligonucleotide is an efficient process, ${ }^{[19]}$ since competitive addition of a water molecule to the guanine radical cation is at best a minor process under these conditions where the two biomolecules form a tight complex. A further example of nucleophilic addition to guanine radicals generated by one-electron oxidation was recently identified through the formation of a thymine-guanine addition product involving the $\mathrm{N}(3)$ of the pyrimidine base and the $C(8)$ of the guanine moiety of single stranded DNA fragments.[20] The formation of the $T-G$ intrastrand adduct was found to be more efficient when the thymine and the guanine bases are separated by a cytosine nucleotide. Further work is required to check whether both the lysine-guanine cross-link and the G-T ad- duct are generated within cellular DNA upon exposure to one-electron oxidation agents such as ionizing radiation and highintensity UV laser pulses.

\subsection{Purine 5',8-Cyclonucleosides}

Purine 5',8-cyclopurine 2'-deoxyribonucleosides have been shown to be generated by initial ${ }^{\circ} \mathrm{OH}$-mediated hydrogen abstraction at $\mathrm{C}\left(5^{\prime}\right)$ of $2^{\prime}$-deoxyadenosine and 2'-deoxyguanosine followed by intramolecular addition to $\mathrm{C}(8)$ of the resulting $\mathrm{C}\left(5^{\prime}\right)$ radical.[21] Major efforts have been devoted during the last five years to gain insights into the mechanism of formation of purine 5',8-cyclonucleosides. It was first reported that the reaction of hydrated electrons $\left(\mathrm{e}_{\mathrm{aq}}^{-}\right)$with 8-bromo-2'-deoxyadenosine (8-BrdAdo) gives rise to a high yield of 5 ',8-cyclo-2'-deoxyadenosine (cdAdo) in a $\left(5^{\prime} R\right):\left(5^{\prime} S\right)$ diastereomeric mixture of $6: 1$ in the presence of $\mathrm{K}_{4} \mathrm{Fe}(\mathrm{CN})_{6} \cdot{ }^{[22]}$ Pulse radiolysis revealed the formation of a transient within $20 \mu \mathrm{s}\left(\varepsilon_{\text {max }}=9600 \mathrm{M}^{-1} \mathrm{~cm}^{-1}\right.$ at 360 $\mathrm{nm}$ ), that was assigned to the corresponding aromatic aminyl radical (Scheme 2). A mechanism was proposed involving oneelectron reductive cleavage of the $\mathrm{C}-\mathrm{Br}$ bond to give the $C(8)$ radical, followed by a fast radical translocation from the $\mathrm{C}(8)$ to 
$\mathrm{C}\left(5^{\prime}\right)$ position and finally an intramolecular attack of the $C\left(5^{\prime}\right)$ radical at the $C(8), N(7)$ double bond of the adenine moiety. The rate constant for the cyclization was measured to be $1.6 \times 10^{5} \mathrm{~s}^{-1}$. The rate constants for the reactions of $\mathrm{C}\left(5^{\prime}\right)$ and aminyl radicals with different oxidants were determined by pulse radiolysis methods. The respective rate constants for the reaction of 2'-deoxyadenosin-5'-yl radical with dioxygen, $\mathrm{Fe}(\mathrm{CN})_{6}{ }^{3-}$, and $\mathrm{MV}^{2+}$ in water at ambient temperature were measured to be $1.9 \times$ $10^{9}, 4.2 \times 10^{9}$ and $2.2 \times 10^{8} \mathrm{M}^{-1} \mathrm{~s}^{-1}$. The value for the reaction of aminyl radical with $\mathrm{Fe}(\mathrm{CN}){ }_{6}{ }^{3-}$ is $8.3 \times 10^{8} \mathrm{M}^{-1} \mathrm{~s}^{-1}$.

The UV photolysis of 8-BrdAdo was also shown to lead to $\mathrm{C}(8)$ radical formation through photolytic cleavage of the $\mathrm{C}-\mathrm{Br}$ bond.[23] In methanol, subsequent hydrogen abstraction from the solvent is the main radical reaction; however, in water or acetonitrile, intramolecular hydrogen abstraction from the sugar moiety, leading to the $\mathrm{C}\left(5^{\prime}\right)$ radical, is the major path. Cyclization of the $\mathrm{C}\left(5^{\prime}\right)$ radical, as above, proceeds with a rate constant of $1.8 \times 10^{5} \mathrm{~s}^{-1}$, as determined by laser flash photolysis, in $\mathrm{CH}_{3} \mathrm{CN}$. Product studies from steady-state photolysis in acetonitrile showed the conversion of 8-BrdAdo to cdAdo in $65 \%$ yield and in a diastereoisomeric ratio $\left(5^{\prime} R\right):\left(5^{\prime} S\right)$ of $1.7: 1$

The stereochemical aspects of the 5',8-cyclization process were studied by varying substitution and solvent in free and protected 2'-deoxyadenosin-5' -yl radicals generated under different reaction conditions. ${ }^{[24]}$ An increase of the $\left(5^{\prime} S\right) /\left(5^{\prime} R\right)$ ratio was observed when the bulkiness of the 5 '-hydroxyl protecting group is increased. This observation was explained in terms of steric repulsion between the protecting group and the purine moiety, to favor a $\mathrm{C}\left(5^{\prime}\right)$-endo conformation, whereas the effect of the water solvent in promoting the $\left(5^{\prime} R\right)$-stereoselectivity in the $5^{\prime}, 8$-cyclization was ascribed to an intramolecular hydrogen bonding, stabilizing the $\mathrm{C}\left(5^{\prime}\right)$-exo conformation. The whole cascade utilized a synthetically useful radical process which allows for the one-pot conversion of 8-BrdAdo into cdAdo to give a diastereoisomeric ratio that depends on the experimental conditions. It was recently reported[25] that under sunlight exposure $\left(5^{\prime} S\right)$-cdAdo photoisomerizes irreversibly to the $\left(5^{\prime} R\right)$ diastereomer. This finding could have biological significance since the latter isomer is the more easily repaired lesion when these purine cyclonucleoside lesions are formed in DNA.

Similar 5',8-cyclization products were obtained from the reaction of hydrated electrons $\left(\mathrm{e}_{\mathrm{ag}}{ }^{-}\right)$with 8-bromo-2'-deoxyinosine (dIno).[26] Pulse radiolysis revealed that one-electron reductive cleavage of the $\mathrm{C}-$ $\mathrm{Br}$ bond gives the $\mathrm{C}(8)$ radical followed

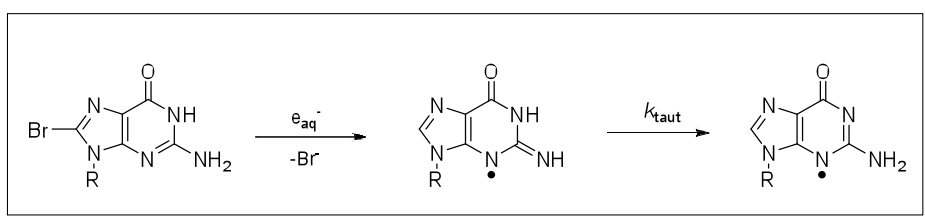

Scheme 3. Formation of oxidizing 2'-deoxyguanosine tautomeric radicals by one-electron reduction of 8-bromo-2'-deoxyguanosine

by a fast translocation of the radical site to the sugar moiety. Selective generation of a $\mathrm{C}\left(5^{\prime}\right)$ radical occurs in the $2^{\prime}$-deoxyriboderivative which undergoes 5 ',8-cyclization, with a rate constant of $1.4 \times 10^{5} \mathrm{~s}^{-1}$ The conversion of dIno to 5 ',8-cyclo- 2 ' deoxyinosine occurs to give a $\left(5^{\prime} R\right) /\left(5^{\prime} S\right)$ diastereoisomeric ratio of $4: 1$.

The corresponding 5',8-cyclization in 2 '-deoxyguanosine was studied in both organic solvents ${ }^{[27]}$ and aqueous solutions. ${ }^{[28]}$ The generation of 2'-deoxyguanosin-5'-yl radicals is effected by the photolysis of synthetic $\left(5^{\prime} R\right)-\mathrm{C}\left(5^{\prime}\right)$ tert-butyl ketone derivatives of dGuo. ${ }^{[27]}$ The photochemistry of the ${ }^{\prime}$ ' $R$ diastereomer effectively produces the 2'-deoxyguanosin-5'-yl radical which undergoes intramolecular attack at the $\mathrm{C}(8)$ $\mathrm{N}(7)$ double bond of guanine leading ultimately to the 5',8-cyclo-2'-deoxyguanosine (cdGuo) derivative. The cyclization of the 2'-deoxyguanosin-5'-yl radical having the 5'-O-TBDMS substituent occurs with a rate constant of $c a .1 \times 10^{6} \mathrm{~s}^{-1}$ and is highly stereoselective, affording only the $\left(5^{\prime} S\right)$-diastereomer of the corresponding 5',8-cdGuo derivative. On the other hand, both $\gamma$-irradiation of dGuo, under hydroxyl radical generating conditions and photolysis of 8-BrdGuo in aqueous solutions leads to the formation of cdGuo in a $\left(5^{\prime} R\right) /\left(5^{\prime} S\right)$ ratio of $8: 1 .{ }^{[28]}$ The diversity of the stereochemical outcome in both systems was rationalized in terms of steric hindrance in the protected pro $\left(5^{\prime} S\right)$ chair transition state versus favorable hydrogen bonding in the unprotected pro- $(5, R)$ conformation, respectively, as was previously reported for the cdAdo system. ${ }^{[22,24]}$

\subsection{Generation of One-electron Oxidized 2'-Deoxyguanosine Tautomers}

The reaction of $\mathrm{e}_{\mathrm{aq}}{ }^{-}$with 8-BrdGuoleads quantitatively to dGuo. Pulse radiolysis experiments, coupled with time-dependent (TD) DFT calculations at the B3LYP/6$31 \mathrm{G}^{*}$ level, revealed that the two previously observed transients correspond to the iminic and aminic tautomeric forms of the guanyl radical (Scheme 3). [29] In a full account of this work, ${ }^{[30]}$ the rate constants for the reactions of $\mathrm{e}_{\mathrm{aq}}{ }^{-}$with a variety of 8-substituted guanine derivatives were measured by pulse radiolysis and correlate with both inductive and resonance components of the substituents. The fate of the electron ad- ducts was investigated by radiolytic methods coupled with product studies and addressed computationally by means of timedependent DFT (TD-B3LYP/6-311G**// B1B95/6-31+G**) calculations. Two tautomeric forms (i.e. iminic and aminic forms, Scheme 3) of one-electron oxidized Guo (or dGuo) are produced by reaction of $\mathrm{e}_{\mathrm{aq}}{ }^{-}$with 8-haloguanosine or 8-halo-2'-deoxyguanosine, whereas only one tautomer is formed by oxidation of Guo (or dGuo). From theory it is suggested that the electron adducts of 8-bromoguanine derivatives protonate at $\mathrm{C} 8$ to form a very short lived $\pi$-complex, with the $\mathrm{Br}$ atom situated above the molecular plane with prompt ejection of $\mathrm{Br}^{-}$. The first observable species decays by first-order kinetics to produce the second intermediate, which is also obtained by oxidation of Guo by $\mathrm{SO}_{4}{ }^{-}$. The rate of tautomerization $\left(k_{\text {taut }}=5 \times 10^{4} \mathrm{~s}^{-1}\right.$ at $\left.22^{\circ} \mathrm{C}\right)$ is strongly accelerated by phosphate but is retarded in $\mathrm{D}_{2} \mathrm{O}$ (kinetic isotope effect 7). The spin density distributions of the two tautomers are quite different at the $\mathrm{O}(6)$ and $\mathrm{N}(10)$ positions, but are very similar at the $\mathrm{N}(3), \mathrm{C}(5)$, and $\mathrm{C}(8)$ positions.

The study above was extended to the 2 -aminoadenosine (2AAdo) system in order to investigate the generality of tautomerism in purine radicals.[31] Two tautomeric forms of one-electron oxidized 2AAdo are produced by reactions of $\mathrm{e}_{\mathrm{aq}}{ }^{-}$with 8-bromo-2-aminoadenosine (8-Br-2AAdo) at natural $\mathrm{pH}$. Tailored experiments by pulse radiolysis and time-dependent DFT (TDB3LYP/6-311G**//B1B95/6-31+G**) calculations allowed the reaction mechanism to be defined in some detail. The electron adducts of $8-\mathrm{Br}-2 \mathrm{AA}$ protonate at $\mathrm{C}(8)$ eject $\mathrm{Br}^{-}$and produce the two short-lived tautomers. B1B95/6-31+G** calculations showed that the tautomerization is a water-assisted process. $\gamma$-Radiolysis of $8-\mathrm{Br}$ 2AAdo in aqueous solution leads to the formation of 2AAdo as a single product as determined by product analysis.[32]

In conclusion, there is a dichotomy within the reaction of 8-halopurine nucleosides with $\mathrm{e}_{\mathrm{aq}}{ }^{-}$. The 8-bromo derivatives of dAdo and dIno react with expulsion of $\mathrm{Br}^{-}$, resulting in the formation of purine 5, 8 -cyclonucleosides. On the other hand, the 8-bromo derivatives of dGuo and 2AAdo react to give a stable radical anion that rapidly protonates with expulsion of $\mathrm{Br}^{-}$, leading to a tautomeric form of the one-electron oxi- 
dized base. From theoretical considerations the behavior of 8-bromopurine derivatives with respect to hydrated electrons can be attributed to differences in the energy gap between the $\pi^{*}$ - and $\sigma^{*}$ - radical anions.[26,30]

\subsection{Reductive Reactions in the Photolyase-mediated Repair of Bipyrimidine Photoproducts}

Electrochemistry has proven to contribute significantly to the understanding of charge transfer through DNA, both for hole (positive charge) transfer and excess negative charge transfer. In particular, knowledge of the electronic conductive properties accumulated from electrochemical studies of nucleic acids and also small oligonucleotides, both freely diffusing in solution or assembled onto electrode surfaces, gives a rational molecular basis for deciphering mechanisms. ${ }^{[3 c]}$ Electrochemical techniques, although less often used than spectroscopic methods, may give insights into DNA damage processes (e.g. from electrochemical generation of radicals issued from the reductive cleavage of 5-halobases or proton-coupled electron transfer processes) and in DNA repair, as it is the case in the chemical repair modeling of DNA photo-induced bipyrimidine lesions (cyclobutane pyrimidine dimers CPDs), (Scheme 4) and pyrimidine (6-4) pyrimidone photoproducts (6-4PPs) by photolyase enzymes.

Biochemical studies made to date indicate that photoreactivation is achieved via a cyclic electron transfer mechanism. [3a] After binding to the damaged DNA strand and flipping the lesion out, the enzyme absorbs a photon (300-500 nm) via the photoantenna cofactor, MTHF (methylenetetrahydrofolate), which then transfers energy to the flavin. The singlet excited state ${ }^{1}\left(\mathrm{FADH}^{-}\right)^{*}$ reduces $\mathrm{CPDs}$ with one electron. The two $\mathrm{C}(5)-\mathrm{C}\left(5^{\prime}\right)$ and $\mathrm{C}(6)-$ $\mathrm{C}\left(6^{\prime}\right)$ bonds of the cyclobutane ring are successively broken to form two monomers, one neutral and one a radical anion. The catalytic cycle is stopped by the oxidation of the radical pyrimidine anion which returns an electron to the neutral flavin $\mathrm{FADH}^{\circ}$, thus regenerating the active form $\mathrm{FADH}^{-}$. Cyclic voltammetry has been used to study the reduction of cyclobutane dimers of $N, N$ '-methylated pyrimidines (e.g. 1,3-dimethylthymine, DMThy, and 1,3-dimethyluracil, DMUra) with differing configurations around the central ring, at carbon electrodes in organic aprotic media $(N, N$ '-dimethylformamide and acetonitrile). [33] The main conclusions arising from these voltammetric studies are that all compounds are irreversibly cleaved with two electrons per substrate molecule. The reduction always goes through the formation of a radical anion as a transient intermediate (too unstable to

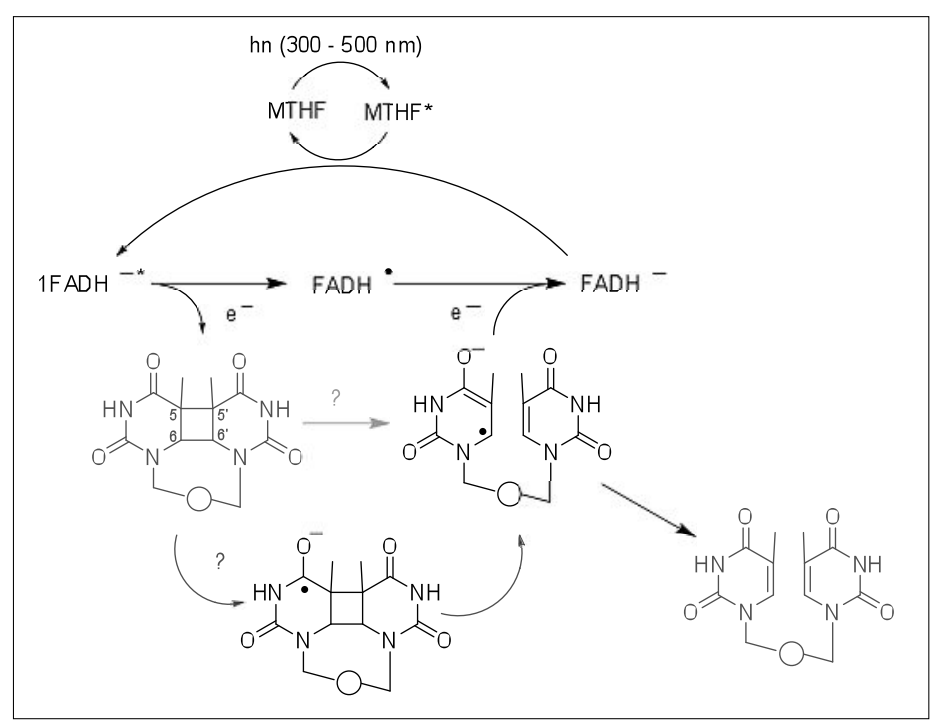

Scheme 4. Proposed catalytic electron transfer mechanism for the repair of CPDs by DNA photolyase

be directly detected), followed by successive homolytic cleavage of the $\mathrm{C}(5)-\mathrm{C}\left(5^{\prime}\right)$ and $C(6)-C\left(6^{\prime}\right)$ bonds of the cyclobutane motif, which affords a radical anion and a neutral monomer. The reduction is not a concerted process. Syn isomers are more easily reduced than anti isomers whilst the cis vs. trans stereochemistry has little influence on the redox properties of the CPDs. In some cases, conditions in which kinetics are governed solely by the charge transfer could be obtained and the standard potential for the radical anion formation calculated (e.g. $-2.62 \mathrm{~V}$ vs. SCE in the case of the cis,syn-DMThy $\leftrightarrow$ DMThy dimer). From these values, the driving force for the photo-induced repair could be estimated and reinforced the hypothesis that a stepwise pathway is likely to be followed during enzymatic repair of CPDs in DNA. ${ }^{[34]}$ Electrochemistry has also proven useful in investigating more directly enzymatic repair. ${ }^{[35]}$ The repair of a model compound ( $c, s$-DMThy $\leftrightarrow$ DMThy) by $E$. coli DNA photolyase has been performed using cyclic voltammetry, on a carbon electrode. The oxidation signal of the substrate, with height proportional to dimer concentration, was used to probe repair. It appears that $E$. coli DNA photolyase effectively recognizes (through hydrogen bonds) and repairs the dimer. Although promising, these results need confirmation by analysis of the biomimetic substrates (e.g. with short DNA strands) and detection of products by analytical techniques (e.g. HPLC) is required.

Specific photolyase enzymes repair 6-4PPs.[3a,36] One speculative mechanism (although alternative mechanisms should not be dismissed) involves the catalyzed formation of an oxetane intermediate when the protein binds to DNA strand and flips the lesion out. Electron transport may occur to this thermally unstable intermediate from the excited state of the flavin in a reduced and protonated state $\mathrm{FADH}^{-}$, yielding two 'repaired' pyrimidine bases after successive cleavage of the oxetane $\mathrm{C}-\mathrm{O}$ and $\mathrm{C}-\mathrm{C}$ bonds. Electrochemical reduction of model oxetanes (obtained from Paterno-Büchi photocycloaddition of DMThy with benzophenone and substituted benzaldehydes) were performed in the presence of a few equivalents of a weak acid in an aprotic medium (N,N'dimethylformamide). ${ }^{[35 b]}$ Electrochemical reduction leads to the cleavage of the oxetanes in all cases, with injection of the first electron occurring at the carbonyl function on the $\mathrm{C}(4)$ position of the thymine moiety, followed by a second step with heterolytic cleavage of the $\mathrm{C}-\mathrm{O}$ bond and subsequent homolytic cleavage of the $\mathrm{C}(6)-\mathrm{C}(7)$ bond. This yields the radical anion of the aromatic carbonyl and the neutral thymine base. The latter species immediately picks up an electron, thus voltammetric waves involve the injection of three electrons per reduced molecule. Mechanisms based on reduction of this oxetane mimic always follow a sequential pathway, although radical anion intermediates are too short lived to be directly probed, and show high similarity with the mechanisms involved in the cleavage of CPDs.

\section{Radical Oxidation of the Guanine Base in Cellular DNA}

Exposure of human THP1 monocytes to gamma rays has been found to lead to the formation of 8-oxo-7,8-dihydro-2'deoxyguanosine and FaPyGua with a respective yield of 20 and 39 lesions per $10^{9}$ bases and per Gy. ${ }^{[37]}$ The two latter guanine degradation products, in addition to relat- 
ed adenine modified compounds and six modified pyrimidine nucleosides including 5-(hydroxymethyl)-2'-deoxyuridine, 5-formyl-2'-deoxyuridine and the four cis and trans diastereomers of 5,6-dihydroxy5,6-dihydrothymidine (ThdGly), have been measured after suitable enzymatic hydrolysis by the accurate and sensitive HPLC-MS/ MS method.[31] Indirect evidence for the major implication of ${ }^{\bullet} \mathrm{OH}$ in the formation of the radiation-induced purine and pyrimidine base lesions came from the significant decrease in the yield of their formation with an increase in the linear energy transfer (LET) value of the two high energetic ${ }^{12} \mathrm{C}^{6+}$ and ${ }^{36} \mathrm{Ag}^{18+}$ heavy ions. This was rationalized in terms of a decrease in the radiolytic yield of ${ }^{\circ} \mathrm{OH}$ as the result of a more efficient recombination of the latter radicals with increasing LET. Another argument to ruling out a major contribution of an ionization process as a result of the direct effect to the molecular action of gamma rays, relies on consideration of the distribution profile of the oxidized nucleosides that have been generated in cellular DNA upon exposure to high intensity UVC laser pulses.[38] Under the latter conditions, 8-oxodGuo which is likely formed in a hydration reaction of the guanine radical cation ${ }^{[39]}$ is overwhelming despite the fact that both pyrimidine and purine bases are photo-ionized with a similar efficiency. The latter specificity may be explained in terms of charge transfer reactions to the guanine bases that are considered as sinks for positive holes.[40] Therefore if one considers that the relative yield of thymidine oxidation products is about seven fold-higher than that of 8-oxodGuo upon exposure to gamma rays it may be concluded that the ionization process contributes less than that of ${ }^{\circ} \mathrm{OH}$ reactions. Therefore the radiation-induced formation of 8-oxodGuo and FaPyGua may be rationalized in terms of ${ }^{\circ} \mathrm{OH}$ addition at $\mathrm{C} 8$ of the guanine base followed by oxidation and reduction respectively (Scheme 5).

It is worth noting that one-electron reduction of transient 8-hydroxy-7,8-dihydroguanyl radical predominates over the competitive molecular oxygen-mediated oxidation reaction. Another example of the validation in cells of ${ }^{\circ} \mathrm{OH}$-mediated oxidation reactions of guanine, previously established in model systems, comes from the recent HPLC-MS/MS detection of 2,2-diamino-4-[(-2-deoxy- $\beta$-D-erythropentofuranosyl)amino]-5(2H)-oxazolone (dZ) in hepatic DNA of diabetic rat.[7] The formation of $\mathrm{dZ}$ in about 10-fold lower yield than that of 8-oxodGuo may be explained by initial addition of ${ }^{\circ} \mathrm{OH}$ at $\mathrm{C}(4)$ followed by dehydration and subsequent addition of $\mathrm{O}_{2}{ }^{--}$resulting in $\mathrm{G}(-\mathrm{H})^{\bullet}{ }^{\cdot}{ }^{[41]}$ Following several rearrangements the transiently formed 2'-deoxyribonucleoside derivative of 2,5-diamino- $4 \mathrm{H}$-imidazol-4-one

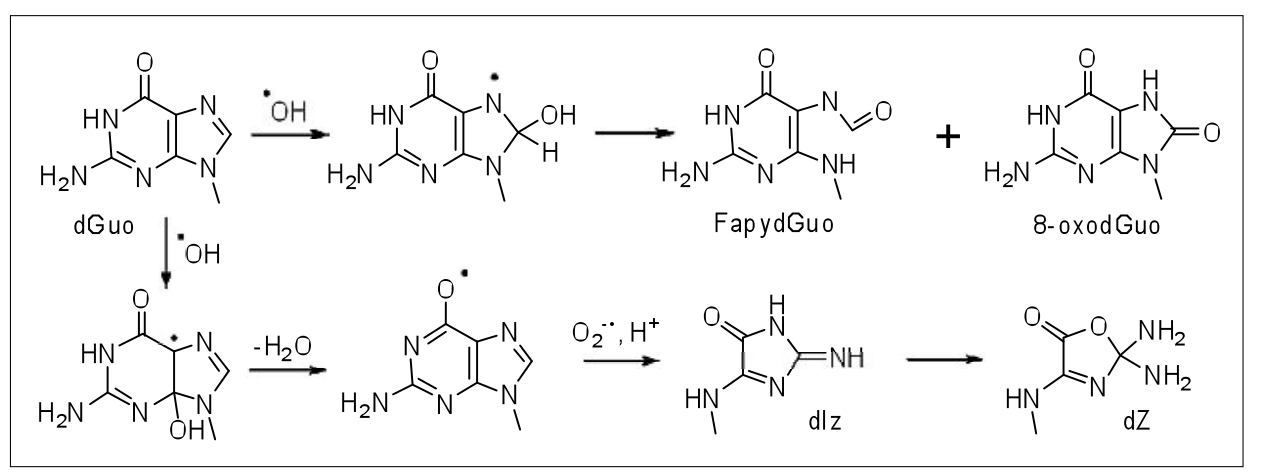

Scheme $5 .{ }^{\bullet} \mathrm{OH}-$ Mediated oxidation reactions of the guanine moiety in cellular DNA

(dIz) is then hydrolytically converted into $\mathrm{dZ}$ (Scheme 5).

\section{Stabilized Oxidative DNA Lesions for the Structural Investigation of the Lesion Recognition Step in Base Excision Repair (BER)}

Oxidatively generated lesions are frequent DNA damages which occur due to the reaction of reactive oxygen species such as ${ }^{\bullet} \mathrm{OH},{ }^{\bullet} \mathrm{OOH},{ }^{1} \mathrm{O}_{2}$ or just $\mathrm{H}_{2} \mathrm{O}_{2}$ with nucleobases. [42] Guanine possesses, among all bases, the lowest oxidation potential and is therefore the prime target for oxidative degradation. ${ }^{[43]}$ Oxidative DNA lesions are frequently highly mutagenic and can induce cell death.[44] In order to avoid these negative effects cells have evolved a variety of repair factors, which are able to recognize such lesions. ${ }^{[45]}$ These proteins initiate a repair process resulting in the replacement of the damaged base by a new nucleobase. The mechanisms by which repair enzymes recognize lesions remain enigmatic.[46] These enzymes have to be able to detect single lesions within vast numbers of mostly undamaged bases. Crystal structures of a number of DNA glycosylases in complex with lesion-containing DNA have been solved and show that these enzymes flip the lesions out of the duplex units change into their active site, where the $N$-glycosidic bond between the 2-deoxyribose and the damaged base is cleaved by a nucleophilic attack at the $\mathrm{C}(1)$ position. ${ }^{[47]}$

The critical question remaining to be answered is how these enzymes are able to flip out only the damaged base while leaving the undamaged ones inside the DNA duplex. This question is particularly delicate because most repair enzymes recognize a large set of different damaged bases showing that the identification of the damaged base itself is promiscuous.

In order to 'trap' the enzyme in lesion recognition states, Verdine and co-workers have linked DNA strands containing either lesions or which are undamaged to the repair glycosylase with the help of designed disulfide bonds. ${ }^{[48]}$ This approach allowed them to crystallize complexes, representing recognition states before the damaged base is completely flipped out. Based on these studies it was proposed that the repair glycosylases might flip out all bases, but first into a pre-binding site (exo-site), where the bases are verified and only the damaged ones are then allowed to access the active site. A phenylalanine side chain was found to be critical for the flipping step and its aromatic ring is supposed to be 'punched' into the duplex to initiate the flipping. [48]

This recognition scenario was recently questioned by Stivers and co-workers who investigated the repair enzyme uracil glycosylase which removes uracil bases formed as the result of cytosine deamination, from DNA. ${ }^{[49]}$ Using artificial dT-purine base pairs without formed $\mathrm{H}$-bonds between the bases, this group developed the theory that repair enzymes might not actively flip out bases but might identify and stabilize spontaneous flipped out states. Since damaged bases have a higher probability to be in a spontaneous flipped out state, this could explain some of the observed selectivity.

Recently efforts were made to look into the problem of lesion recognition in more detail. The general approach is to study the recognition event with DNA and enzymes that are only minimally disturbed. Therefore fully active wild type enzymes were investigated while avoiding working with artificially linked systems or unnatural base pairs. In order to stabilize the complexes between the repair enzyme and the DNA we began to prepare bio-isoteric lesion analogs (Fig. 1), which can be bound but not repaired by the enzyme.[50]

So far the synthesis of the analogues of the 8-oxodGuo, FaPydGuo and FaPydAdo, all containing a carbocyclic cyclopentane skeleton instead of the 2-deoxyribose, has been completed. Previous physical organic studies have shown that this small chemical perturbation does not change the properties of the compound and in particular the $\mathrm{H}$ bonding capabilities. ${ }^{[51]}$

Recently the first crystal structure (Fig. 2) of the DNA glycosylase MutM in com- 

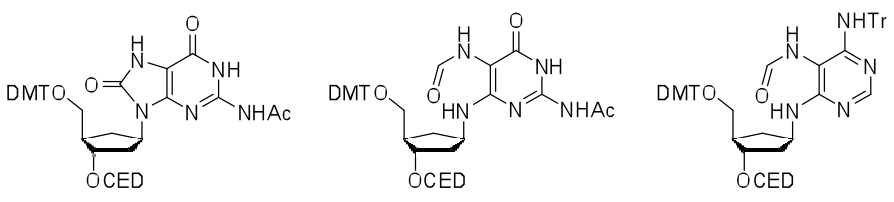

Fig. 1. Phosphoramidite building blocks of the carbocyclic lesion analogs of 8-oxodGuo, FaPydGuo, and FaPydAdo (from left to right) for solid phase incorporation into DNA

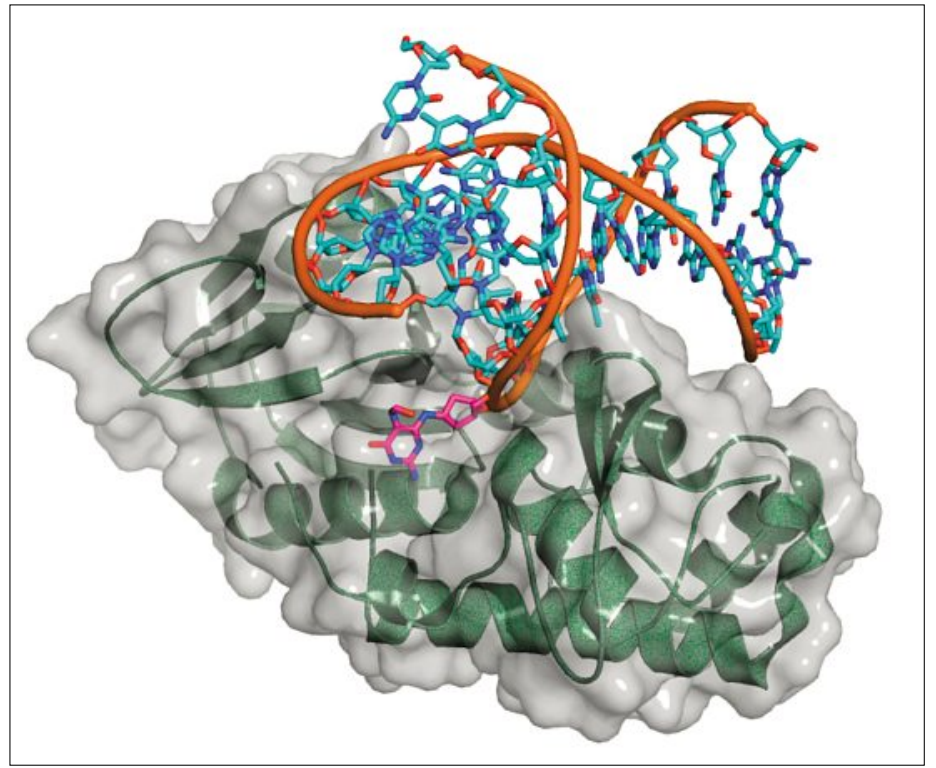

Fig. 2. Structure of the repair glycosylase MutM in complex with DNA that contains the stabilized FaPydG analog

plex with the lesion analogue of FaPydGuo could be obtained.[52] Further expected crystal structures of the various lesion analogues in complex with DNA glycosylases will provide a detailed picture of how oxidative DNA lesions are recognized by these important repair enzymes present in all organisms.

\section{Repair of Oxidatively Generated Clustered Damage to DNA}

In normal aerobic metabolism, reactive oxygen species are produced which may interact with DNA to give a variety of endogenously generated lesions. Many of these DNA lesions are chemically indistinguishable from those produced in mammalian cells by ionizing radiations. However the detrimental effects of ionizing radiation and some radio-mimetic drugs are thought to arise largely from the unique ability of radiation to induce clustered DNA damage, which includes double strand breaks (DSB), when two or more lesions occur within one or two helical turns of the DNA by the passage of a single radiation track. ${ }^{[53]}$ The DNA lesions induced by ionizing radiation are formed through either the direct deposition of energy in DNA or through reaction of free radicals, produced from radiolysis of water molecules close to the DNA. [54]

Predictions from biophysical models of interactions of radiation tracks with DNA indicate that significant levels of DNA lesions are formed in clusters and that the complexity of the clusters increases with increasing ionization density of the radiation. ${ }^{[55]}$ Consistent with this prediction are the increased biological effects such as mutagenesis, carcinogenesis and lethality. Recent studies have verified that non-DSB clustered DNA damage sites are induced in mammalian cells ${ }^{[53 b, 56]}$ and $E$. coli ${ }^{[57]}$ by ionizing radiation. The yield of non-DSB clustered damage is greater than that of DSB and only a small sub-class of these nonDSB clustered damaged sites are converted to DSB post-irradiation. ${ }^{[57,58]}$

To minimize the biological consequences of single lesions such as those induced endogenously, the base excision repair (BER) pathway (reviewed[59]) has evolved to repair small DNA lesions, such as those produced by endogenous reactive oxygen species, and is largely responsible for the removal of many lesions induced by ionizing radiation. It has been hypothesized that radiationinduced clustered damage sites are however less repairable than isolated lesions and are therefore particularly harmful to cells. Sites of non-DSB clustered DNA damage induced by radiation in cells commonly consist of closely-associated base lesions, apurinic/ apyrimidinic (AP) sites or SSB, as verified by both in vitro and in vivo analyses. ${ }^{[53 b, 56]} \mathrm{A}$ number of recent studies using model systems of clustered DNA damage sites comprised of bistranded lesions have established that the BER pathway of prokaryotes and eukaryotes is challenged by clustered DNA damage (reviewed[60,61]). These studies have revealed that the efficiency of repair of the clustered lesion is dependent on the types of lesions within the cluster, the inter-lesion distance and the relative orientation of the lesions to each other.

From the findings on the processing of non-DSB bistranded clusters, a general mechanism of repair is beginning to emerge. With bistranded clusters containing two AP sites a DSB is formed when processed by endonucleases unless the AP sites are within three base pairs (bp) of each other in a 5' orientation. ${ }^{[62]}$ In contrast a bistranded cluster containing two base lesions tends not to be converted into a DSB. For example, the efficiency of removal of one of the base lesions by a BER glycosylase is only reduced if the other base lesion is within one bp. However the consequence of removal of one of the base lesions is that the ensuing AP site is rapidly converted into a SSB, as incision of the AP site by AP endonuclease(s) is unaffected by the presence of the opposing base lesion. Therefore formation of a SSB opposite a base damage is favored and as a consequence may drastically retard excision of the opposing base lesion by a glycosylase, ${ }^{[60,63]}$ so that formation of a DSB is minimized. However a proportion of the SSB sites, when bistrandedly clustered with a base lesion, is less efficiently rejoined dependent upon their proximity to the base lesion.[63] As a consequence the SSB and the base lesion will have an enhanced lifetime and if in cycling cells, may persist through to replication and depending upon the type of base lesion, be deleterious.

The mutagenic potential of bistranded clustered damage sites containing a mixture of lesions in Escherichia coli or mammalian cells has been shown to be high relative to that of the isolated lesions. ${ }^{[64]}$ More recently the efficiency/abundance of the base glycosylase such as endonuclease III in E. coli has also be shown to play a decisive role in the initial stages of processing of clusters containing different base lesions. [64f]

Less is know about the efficiency of processing of tandem lesions although some evidence shows that tandem damaged sites can compromise the repair machinery of the cell and lead to an increase in the mutation frequency of the constituent lesions. ${ }^{[65]}$ 
With the recent findings that a single ${ }^{\circ} \mathrm{OH}$ induces complex tandem lesions, ${ }^{[7 \mathrm{~b}]}$ their biological relevance is an area ripe for investigation.

\section{Conclusions}

The few examples of formation and repair of DNA damage that are reported in this short review illustrate the diversity of radical-mediated reactions of nucleobases and 2-deoxyribose moiety and the complexity of biochemical pathways involved in the removal of the lesions from the genome. The various chemical, analytical, biochemical and structural biology approaches that are involved in these studies also underline the existence of a wide and unique set of complementary expertise within the network. This should allow through cooperative efforts excellent opportunities to tackle ambitious investigations on DNA damage and repair.

\section{Acknowledgements}

The support and sponsorship by COST Action CM0603 on 'Free Radicals in Chemical Biology (CHEMBIO-RADICAL)' are kindly acknowledged.

Received: July 10, 2008

[1] a) J. Cadet, T. Douki, D. Gasparutto, J.-P. Pouget, J.-L. Ravanat, S. Sauvaigo, Mutat Res. 1999, 424, 9; b) H. C. Box, J. B. Dawidzik, E. E. Budzinski, Free Radic. Biol. Med. 2001, 31, 856; c) M. M. Greenberg, Org. Biomol. Chem. 2007, 5, 18; d) A. G. Georgakilas, Mol. Biosyst. 2008, 4, 30.

[2] P. C. Dedon, Chem. Res. Toxicol. 2008, 21, 206.

[3] a) A. Sancar, Chem. Rev. 2003, 103, 2203; b) S. Weber, Biochim. Biophys. Acta $\mathbf{2 0 0 5}$, 1707,1 ; c) M. Byrdin, S. Villette, A. P. M. Eker, K. Brettel, Biochemistry 2007, 46, 10072; c) F. Boussicault, M. Robert, Chem. Rev. 2008 108, 2622.

[4] a) J. Cadet, T. Douki, D. Gasparutto, J.L. Ravanat, Mutat. Res. 2003, 531, 5; b) T. Gimisis, C. Cismas, Eur. J. Org. Chem. 2006, 1351; c) G. Pratviel, B Meunier, Chem.-Eur. J. 2006, 12, 6018; d) C. von Sonntag, 'Free-radical induced DNA damage and its repair. A chemical perspective', Springer, Heidelberg, 2006; e) J. Cadet, D. Douki, J.-L. Ravanat, Acc. Chem. Res. 2008, 41, 1075.

[5] a) H. J. Helbock, K. B. Beckman, M. K Shigenaga, P. B. Walter, A. A. Woodall, H. C. Yeo, B. N. Ames, Proc. Natl. Acad. Sci. USA 1998, 95, 288; b) J. Cadet, T. Douki, S. Frelon, S. Sauvaigo, J.-P. Pouget, J.-L. Ravanat, Free Radic. Biol. Med. 2002 33, 441; c) J.-L. Ravanat, T. Douki, P. Duez, E. Gremaud, K. Herbert, T. Hofer, L. Lasserre, C. Saint-Pierre, A. Favier, J. Cadet, Carcinogenesis 2002, 23, 1911.

[6] a) ESCODD., Free Radic. Biol. Med. 2003, 34, 1089; b) A. R. Collins, J. Cadet, L. Möller, H. E. Poulsen, J. Viña, Arch. Biochem. Biophys. 2004, 423, 57.
[7] a) B. Matter, D. Malejka-Giganti, A.S. Csallany, N. Tretyakova, Nucleic Acids Res. 2006, 34, 5449; b) P. Regulus, B. Duroux, P.A. Bayle, A. Favier, J. Cadet, J.-L. Ravanat, Proc. Natl. Acad. Sci. USA 2007, 104, 14032.

[8] a) D. M. Wilson III, T. M. Sofinowski, D. R. McNeill, Front Biosci. 2003, 8, d963; b) D. E. Barnes, T. Lindahl, Annu. Rev. Genet. 2004, 38, 445; c) M. D'Errico, E. Parlanti, E. Dogliotti, Mutat. Res. 2008 659 , 4; d) T. K. Hazra, A. Das, S. Das, S. Choudhury, Y. W. Kow, R. Roy, DNA Repair (Amst) 2007, 6, 470.

[9] a) J. C. Delaney, J. M. Essigmann, Chem. Res. Toxicol. 2008, 21, 232; b) S. Mourgues, J. Trzcionka, J. J. Vasseur, G. Pratviel, B. Meunier, Biochemistry 2008 47, 4788.

[10] a) N. Charlet-Berguerand, S. Feuerhahn, S. E. Kong, H. Ziserman, J. W. Conaway, R. Conaway, J. M. Egly, EMBO J. 2006, 25, 5481; b) W. L. Neeley, S. Delaney, Y. O. Alekseyev, D. F. Jarosz, J. C. Delaney, G. C. Walker, J. M. Essigmann, J. Biol. Chem. 2007, 282, 12741; c) M. d'Abbadie, M. Hofreiter, A. Vaisman, D. Gasparutto, J. Cadet, R. Woodgate, S. Pääbo, P. Holliger, Nat. Biotechnol. 2007, 25, 939.

[11] a) S. Bjelland, E. Seeberg, Mutat. Res. 2003, 531, 37; b) W. L. Neeley, J. M. Essigmann, Chem. Res. Toxicol. 2006, 19, 491; c) Y. Nakabeppu, K. Sakumi, K. Sakamoto, D. Tsuchimoto, T. Tsuzuki, Y. Nakatsu, Biol. Chem. 2006, 387, 373.

[12] a) J. Cadet, A. G. Bourdat, C. d'Ham, V. Duarte, D. Gasparutto, A. Romieu, J.L. Ravanat, Mutat. Res. 2000, 462, 121; b) S. Iwai, Nucleosides Nucleotides Nucleic Acids 2006, 25, 561; c) M. Lukin, C. de los Santos, Chem. Rev. 2006, 106, 607.

[13] S. Steenken, Chem. Rev. 1989, 89, 503.

[14] H. Kasai, Z. Yamaizumi, M. Berger, J. Cadet, J. Am. Chem. Soc. 1992, 114, 9692.

[15] a) J. Cadet, T. Douki, J.-L. Ravanat, Nat. Chem. Biol. 2006, 2, 348; b) Y. A. Lee, B. H. Yun, S. K. Kim, Y. Margolin, P. C. Dedon, N. E. Geacintov, V. Shafirovich, Chem.-Eur. J. 2007, 13, 4571.

[16] B. Giese, M. Spichty, ChemPhysChem $2000,1,195$.

[17] R. N. Barnett, A. Bongiorno, C. L Cleveland, A. Joy, U. Landman, G. B. Schuster, J. Am. Chem. Soc. 2006, 128 , 10795.

[18] L. P. Candeias, S. Steenken, Chem.-Eur. J. 2000, 6, 475.

[19] S. Perrier, J. Hau, D. Gasparutto, J. Cadet, A. Favier, J.-L. Ravanat, J. Am. Chem Soc. 2006, 128, 5703.

[20] C. Crean, Y. Uvaydov, N. E. Geacintov, V Shafirovich, Nucleic Acids Res. 2008, 36 , 742.

[21] P. J. Brooks, DNA Repair (Amst) 2008, 7, 1168

[22] C. Chatgilialoglu, M. Guerra, Q. G. Mulazzani, J. Am. Chem. Soc. 2003, 125 , 3839

[23] L. B. Jimenez, S. Encinas, M. A. Miranda, M. L. Navacchia, C. Chatgilialoglu, Photochem. Photobiol. Sci. 2004, 3 , 1042.
[24] M. L. Navacchia, C. Chatgilialoglu, P. C. Montevecchi, J. Org. Chem. 2006, 71 , 4445.

[25] L. B. Jimenez, S. Encinas, C. Chatgilialoglu, M. A. Miranda, Org. Biomol. Chem. 2008, 6, 1083.

[26] M. Russo, L. B. Jimenez, Q. G. Mulazzani, M. D'Angelantonio, M. Guerra, M. A Miranda, C. Chatgilialoglu, Chem.-Eur. J. 2006, 12, 7684 .

[27] A. Manetto, D. Georganakis, L. Leondiadis, T. Gimisis, P. Mayer, T. Carell, C. Chatgilialoglu, J. Org. Chem. 2007, 72, 3659.

[28] C. Chatgilialoglu, R. Bazzanini, L. B. Jimenez , M. A. Miranda, Chem. Res. Toxicol. 2007, 20, 1820 .

[29] C. Chatgilialoglu, C. Caminal, M. Guerra, Q. G. Mulazzani, Angew. Chem., Int. Ed. 2005, 44, 6030.

[30] C. Chatgilialoglu, C. Caminal, A. Altieri, G. C. Vougioukalakis, Q. G. Mulazzani, T. Gimisis, M. Guerra, J. Am. Chem. Soc. 2006, 128, 13796.

[31] J. P. Pouget, S. Frelon, J.-L. Ravanat, I. Testard, F. Odin, J. Cadet, Radiat. Res. 2002, 157, 589.

[32] P. Kaloudis, M. D'Angelantonio, M. Guerra, T. Gimisis, Q. G. Mulazzani, C. Chatgilialoglu, J. Phys. Chem. B 2008 , 112, 5209.

[33] F. Boussicault, O. Kruger, M. Robert, U. Wille, Org. Biomol. Chem. 2004, 2 , 2742.

[34] a)Y.T. Kao, C. Saxena, L. Wang, A. Sancar, D. Zhong, Proc. Natl. Acad. Sci. USA 2005, 102, 16128; b) C. Chatgilialoglu, M. Guerra, P. Kaloudis, C. Houée-Levin, J. L. Marignier, V. N. Swaminathan, T. Carell, Chem. Eur. J. 2007, 13, 8979.

[35] a) M.C. DeRosa, A. Sancar, J. K. Barton, Proc. Natl. Acad. Sci. USA 2005, 102 , 10788; b) F. Boussicault, M. Robert, J. Phys. Chem. B 2006, 110, 21987.

[36] a) G. Prakash, D. Falvey, J. Am. Chem. Soc. 1995, 117, 11375; b) A. Joseph, G. Prakash, D. Falvey, J. Am. Chem. Soc. 2000, 122, 11219; c) M. G. Friedel, M. K. Cichon, T. Carell, Org. Biomol. Chem. 2005, 3, 1937; d) M. K Cichon, S. Arnold, T. Carell, T. Angew. Chem., Int. Ed. 2002, 41, 767.

[37] S. Frelon, T. Douki, J.-L. Ravanat, J. P. Pouget, C. Tornabene, J. Cadet, Chem. Res. Toxicol. 2000, 13, 1002.

[38] T. Douki, J.-L. Ravanat, J.-P. Pouget, I. Testard, J. Cadet, Int. J. Radiat. Biol. 2006, 82, 119.

[39] T. Douki, J.-L. Ravanat, D. Angelov, J. R. Wagner, J. Cadet, Topics Curr. Chem. 2004, 236,1

[40] a) G. B. Schuster, Acc. Chem. Res. 2000 33, 253; b) E. M. Boon, J. K. Barton, Curr Opin. Struct. Biol. 2002, 12, 320.

[41] a) J. Cadet, M. Berger, G. W. Buchko, P. C. Joshi, S. Raoul, J.-L. Ravanat, $J$. Am. Chem. Soc. 1994, 116, 7403; b) R. Misiaszek, C. Crean, A. Joffe, N. E. Geacintov, V. Shafirovich, J. Biol. Chem. 2004, 279, 32106

[42] J. Cadet, S. Bellon, M. Berger, A.-G. L. Bourdat, T. Douki, V. Duarte, S. Frelon, D. Gasparutto, E. Muller, J.-L. Ravanat, S. Sauvaigo, Biol. Chem. 2002, 383, 933. 
[43] K. Kino, I. Saito, H. Sugiyama, J. Am Chem. Soc. 1998, 120, 7373.

[44] K. Kino, H. Sugiyama, Chem. Biol. 2001, 8, 369 .

[45] E. C. Friedberg, Nature 2003, 421, 436

[46] T. S. James, Chem.-Eur. J. 2008, 14, 786.

[47] a) J. Butenandt, L. T. Burgdorf, T. Carell, Angew. Chem., Int. Ed. 1999, 38, 708; b) R. J. Roberts, Cell 1995, 82, 9; c) P. Varnai, R. Lavery, J. Am. Chem. Soc. 2002, 124, 7272 .

[48] a) A. Banerjee, W. L. Santos, G. L. Verdine, Science 2006, 311, 1153; b) A. Banerjee, W. Yang, M. Karplus, G. L. Verdine, Nature 2005, 434, 612.

[49] J. B. Parker, M. A. Bianchet, D. J. Krosky, J. I. Friedman, L. M. Amzel, J. T. Stivers, Nature 2007, 449, 433

[50] F. Büsch, J. C. Pieck, M. Ober, J. Gierlich, G. W. Hsu, L. S. Beese, T. Carell, Chem.Eur. J. 2008, 14, 2125.

[51] M. Ober, H. Muller, C. Pieck, J. Gierlich, T. Carell, J. Am. Chem. Soc. 2005, 127, 18143.

[52] F. Coste, M. Ober, T. Carell, S. Boiteux, C. Zelwer, B. Castaing, J. Biol. Chem. 2004, 279, 44074.

[53] a) S. Cunniffe, P. O'Neill, Radiat. Res. 1999, 152, 421; b) B. M. Sutherland, P. V. Bennett, O. Sidorkina, J. Laval, Proc. Natl. Acad. Sci. USA 2000, 97, 103; c) B. M. Sutherland, A. G. Georgakilas, P. V. Bennett, J. Laval, J. C. Sutherland, Mutat. Res. 2003, 531, 93.
[54] P. O'Neill, E. M. Fielden, 'Advances in Radiation Biology', Ed. J. T. Lett, W. K. Sinclair, 1993, p. 53.

[55] a) H. Nikjoo, P. Neill, W. E. Wilson, D. T. Goodhead, Radiat. Res. 2001, 156, 577; b) H. Nikjoo, P. O’Neill, M. Terrissol, D. T. Goodhead, Radiat. Environ. Biophys. 1999, $38,31$.

[56] a) M. Gulston, J. Fulford, T. Jenner, C. de Lara, P. O'Neill, Nucleic Acids Res. 2002, 30, 3464; b) B. M. Sutherland, P. V. Bennett, J. C. Sutherland, J. Laval, Radiat. Res. 2002, 157, 611.

[57] O. Blaisdell, S. S. Wallace, Proc. Natl. Acad. Sci. USA 2001, 98, 7426.

[58] M. Gulston, C. de Lara, T. Jenner, E. Davis, P. O’Neill, Nucleic Acids Res. 2004, 32, 1602.

[59] H. Nilsen, H. E. Krokan, Carcinogenesis 2001, 22, 987.

[60] a) F. Barone, E. Dogliotti, L. Cellai, C. Giordano, M. Bjoras, F. Mazzei, Nucleic Acids Res. 2003, 31, 1897; b) G. EotHoullier, M. Gonera, D. Gasparutto, C. Giustranti, E. Sage, Nucleic Acids Res. 2007, 35, 3355; c) G. Eot-Houllier, S. EonMarchais, D. Gasparutto, E. Sage, Nucleic Acids Res. 2005, 33, 260; d) M. E. Lomax, M. Gulston, P. O'Neill, Radiation Protection Dosimetry 2002, 99, 63; e) S. S. Wallace, Free Radic. Biol. Med. 2002, 33, 1.

[61] M. Weinfeld, A. Rasouli-Nia, M. A. Chaudhry, R. A. Britten, Radiat. Res. 2001, 156, 584.
[62] a) M. H. David-Cordonnier, S. M. T. Cunniffe, I. D. Hickson, P. O'Neill, Biochemistry 2002, 41, 634; b) Z. Lin, C. de los Santos, J. Mol. Biol. 2001, 308, 341.

[63] a) M. Lomax, S. Cunniffe, P. O'Neill, Biochemistry 2004, 43, 11017; b) $\mathrm{M}$ E. Lomax, S. Cunniffe, P. O'Neill, DNA Repair (Amst) 2004, 3, 289; c) S. Mourgues, M. E. Lomax, P. O'Neill, Nucleic Acids Res. 2007, 35, 7676.

[64] a) D. I. D'Souza, L. Harrison, Nucleic Acids Res. 2003, 31, 4573; b) S. Malyarchuk, K. L. Brame, R. Youngblood, R. Shi, L. Harrison, Nucleic Acids Res. 2004, 32, 5721; c) S. Malyarchuk, L. Harrison, J. Mol. Biol. 2005, 345, 731; d) S. Malyarchuk, R. Youngblood, A. M. Landry, E. Quillin, L. Harrison, DNA Repair (Amst) 2003, 2, 695; e) C. G. Pearson, N. Shikazono, J. Thacker, P. O'Neill, Nucleic Acids Res. 2004, 32, 263; f) N. Shikazono, C. Pearson, P. O'Neill, J. Thacker, Nucleic Acids Res. 2006, 34, 3722.

[65] S.M. T. Cunniffe, M. E. Lomax, P. O'Neill, DNA Repair (Amst) 2007, 6, 1839. 